\title{
Effectiveness and applicability of flood barriers for risk mitigation in flash- flood prone Mediterranean area
}

\author{
Dario Rappazzo ${ }^{1, a}$ and Giuseppe Tito Aronica ${ }^{1}$ \\ ${ }^{1}$ Dipartimento di Ingegneria, Università di Messina \\ Contrada di Dio, Villaggio S. Agata,98166, Messina, Italy
}

\begin{abstract}
The new policy of flood risk management is to give more attention to non-structural measures, allowing people to "live with floods" rather than "fight floods". To protect existing buildings there are two main mitigation strategies: dry proofing and wet proofing. One measure of dry proofing is the shielding, consisting in the use of flood barriers, which can be installed at the entrance of the buildings or at a certain distance from them (including the placing along the banks or crossing a street). These flood protection structures are easier and faster to install rather than sandbags. This paper shows the results applied to a case study in the city of Barcellona, Sicily, Italy that is crossed by a river and suffered a severe inundation in November 2011. To study the effectiveness of using these flood barriers, a 2D hydrodynamic model has been used: the barriers has been placed along a road to inhibit the flow from flooding the protected area. While in North Europe these types of barriers are commonly used, because those areas are typically interested in clear water floods, in Italy flash floods and mud-debris-flows are more frequent and limit their use. The purpose of this work is to verify if these types of barriers are effective when placed along Mediterranean river courses and, especially, to be sure about their stability while subjected to the hydrodynamic effects of these kind of events. To gain this aim, the computed stresses from the modelling have been compared with the stability values of the barriers provided by the producers, evaluating barriers' stability against overturning and sliding. Simulations show how the flood barriers can mitigate the hydraulic risk, being able to withstand the hydrodynamic pressures and managing to divert the flow of water, thus avoiding that the flood water hits very exposed areas.
\end{abstract}

\section{Introduction}

In recent years around the world, urban floods have become more frequent. This is due in part to the impact of the climate change [1], and above all, to the intensive urbanisation, that produces an increment of impermeable surfaces and consequently an increase in the peak discharge and a decrease of the time of concentration. Therefore, the flood damage to buildings and the risk concerning the safety of human lives have become an important issue. In flood prone areas can be adopted various types of flood protective measures, like dikes, levees, earth embankments. These structural measures need enormous investments, a frequent maintenance and often it is to not possible install them by lack of space. Therefore, to install in some cases it is preferable use non-structural measures. In particular, to protect existing buildings there are two different strategies: wet proofing and dry proofing. With wet proofing the buildings are adapted to flooding allowing in this way to reduce the damage, thanks to the application of water resistant building materials. The dry proofing strategy is to keep floodwater out from the building $[2,3,4]$. One measure of dry proofing is the shielding, consisting in the use of

\footnotetext{
a Corresponding author: drappazzo@unime.it
}

flood barriers, which can be installed at the entrance of the buildings or at a definite distance from them, including the placing along the banks or crossing a street. These flood protection structures are easier and quicker to install rather than sandbags, and to remove. The flood barriers ought to have an acceptable stability against overturning and sliding, and the seepage beneath the structure should be kept at a satisfactory level. There are various kinds of barriers like vertical walls, dihedral structures, water absorption bags, water gravity dams, flexible liners, and folding standby flood defence [5]. With excellent results, these barriers are commonly used in many parts of the world, especially in North Europe because there are typically interested in clear water floods and therefore they can easily withstand the hydrodynamic forces [6]. The Mediterranean climate is different: the intensity of rainfall is higher. Many catchments in Italy have high slope and little size, due to the specific orogeny of the territory, and therefore the climate and the dimension of the Italian catchments are the main causes of the frequent flash floods and mud-debris-flows. The aim of this work is to verify if flood barriers are effective also when placed along Mediterranean river course. 


\section{Case Study}

The Longano river is situated in the North-eastern Sicily, and it crosses the urban center of Barcellona Pozzo di Gotto and the town of Caldera in the coastal strip, before flowing into the Tyrrhenian Sea. The city of Barcellona Pozzo di Gotto, in the province of Messina, covers an area of about $59.14 \mathrm{~km}^{2}$ and includes a population of about 42000 inhabitants.

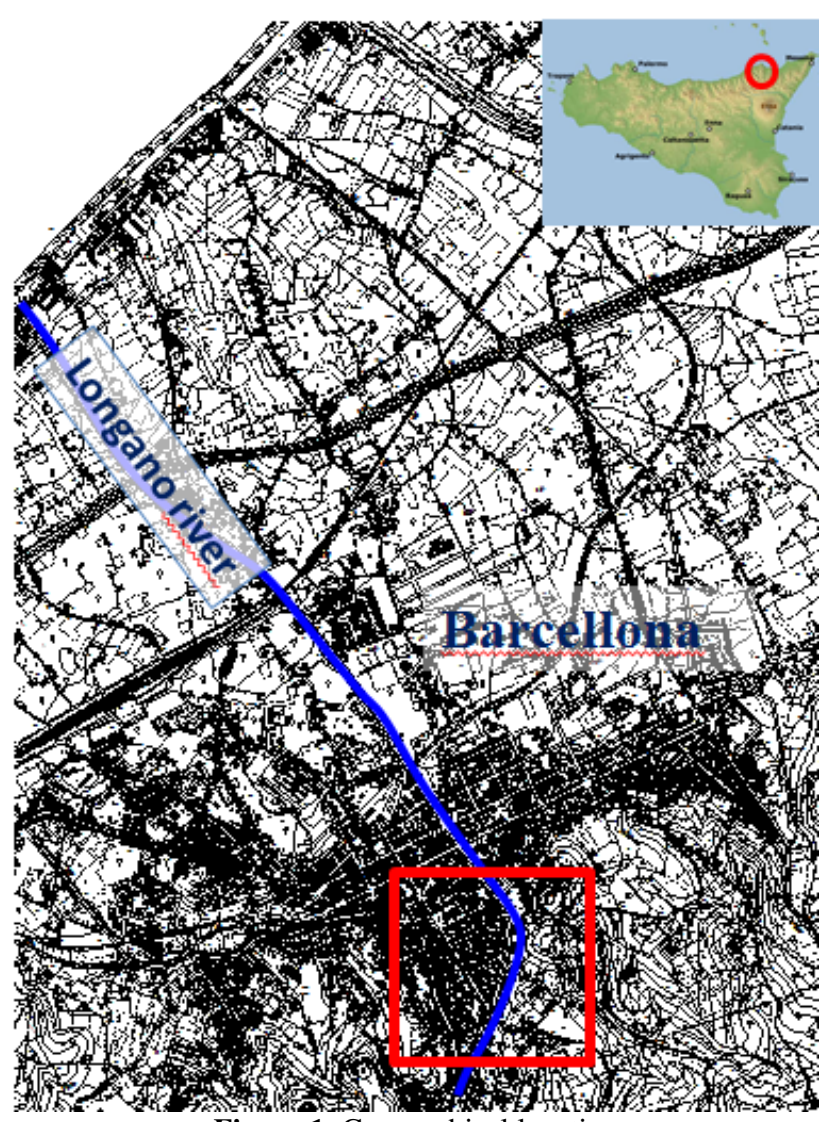

Figure 1. Geographical location

The catchment has an area of $30.7 \mathrm{~km} 2$, reaches $1162 \mathrm{~m}$ s.l.m. with an average slope of $0.18 \%$. The city of Barcellona Pozzo di Gotto, is located in the downstream area of the catchment. The climate is Mediterranean, with a dry season from May to September and a rainy season (October to April), characterized by rainfall events with short durations and high intensity. Precipitation are also strongly influenced by the topography and the prevalence of winds from the North-West. The average annual rainfall is about 904 millimetres, with nearly $83 \%$ in the wet season and $17 \%$ in the dry season. In the years several floods have hit this area, characterized by heavy rainfall, mud flows, debris flows and sudden local flooding. On 22 November 2011, in particular, a rainfall event of high intensity (over 11 hours have fallen 240 $\mathrm{mm}$ of rain) caused the flooding of over 5 million cubic meters of water and solid material, both from bankside openings (dating back to past events), and at some bridges. The critical points where overflows occurred are highlighted in Figure 2.

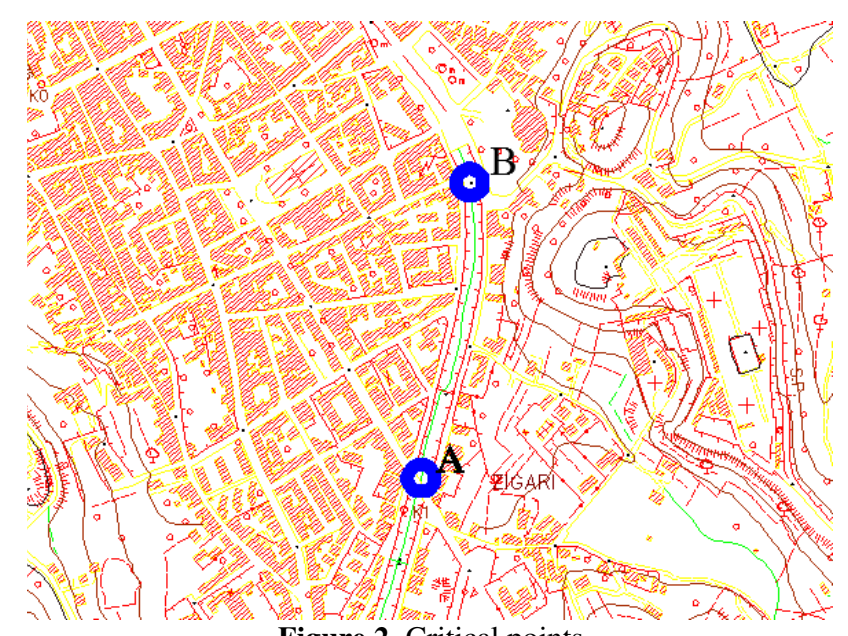

Figure 2. Critical points

In Figure 3 and Figure 4 are shown respectively the critical point $\mathrm{A}$ and the critical point $\mathrm{B}$, after the flooding.

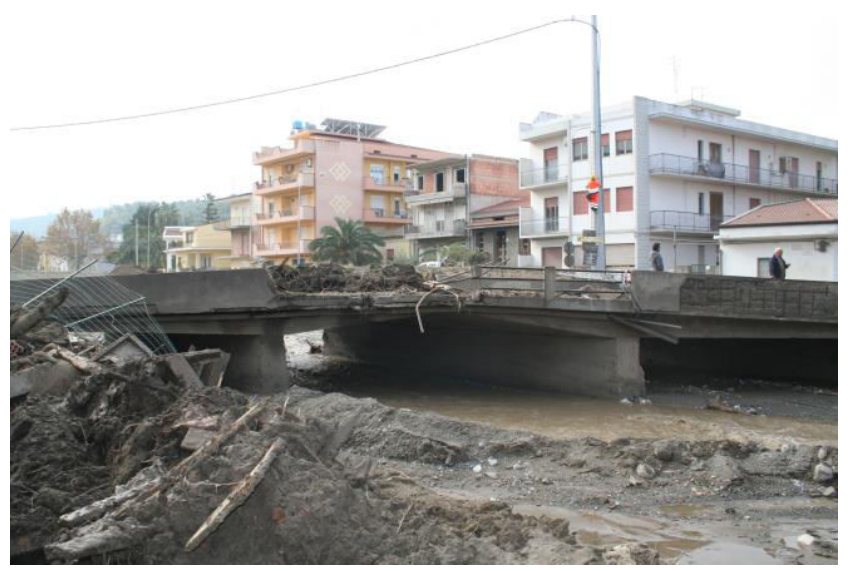

Figure 3. Critical point A

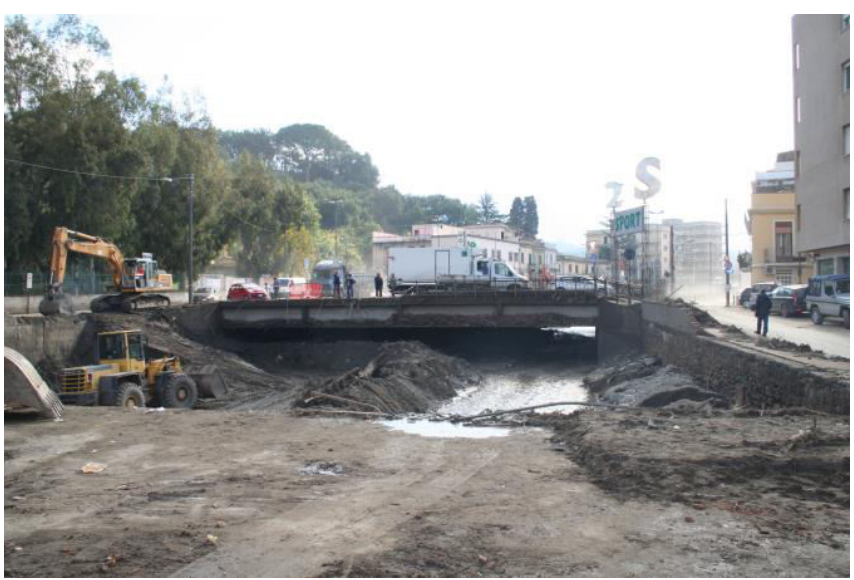

Figure 4. Critical point B

The flooding of the river Longano on 22nd November 2011 caused extensive damage over a large part of the urban center of Barcellona Pozzo di Gotto. In Figure 5 it is clearly visible the watermark consequent to the flood. 


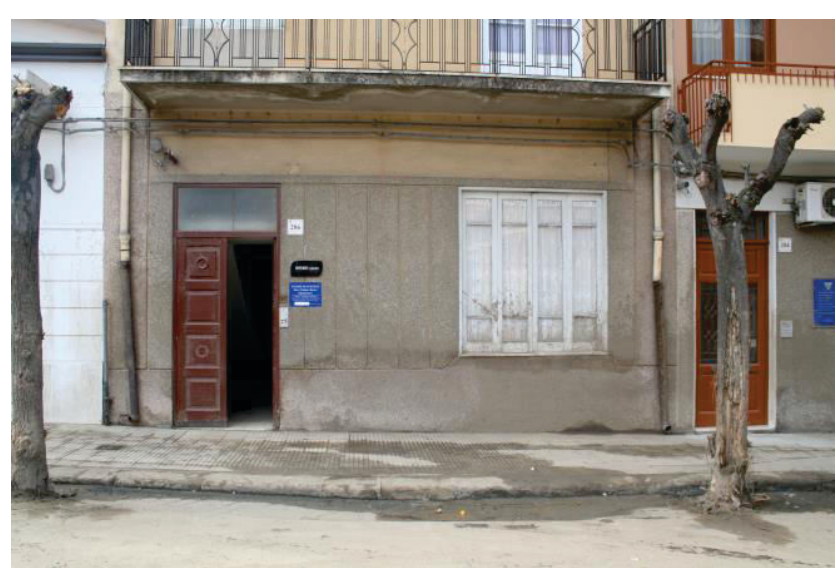

Figure 5. A street after the flood of November 22, 2011

\section{Materials: flood barriers}

Some companies, producing flood barriers, located around the world, were contacted by email, to obtain information on the applicability of various products [7]. The companies contacted are: Flood Panel, Geodesign Barriers, FloodBreak and Dutchdam. The reasons that led us to choose these companies, and not others, are mainly that their products are designed to withstand high hydrodynamic forces. The main features of the barriers of the above companies are described below. The Table, 1 shows the stability values of the barriers provided by the producers. For parallel flow to the barriers, they have a very high resistance force.

\subsection{Features of flood barriers}

\subsubsection{Flood Panel}

The products of the Flood Panel (U.S.A. Florida), are mainly used for the protection of urbanized centres, but they can also act as a temporary levees, before making a concrete foundation, on which then anchor the barriers ( http://www.floodpanel.com/). The system itself can be installed either across specific openings or as a perimeter defense. The system comprises " $C$ " shaped support posts and hollow aluminum beams. The barriers heights ranging from 0.9 to $1.5 \mathrm{~m}$. Flood barrier is a modular system designed to withstand high velocity water loads $(1.5-2.43 \mathrm{~m} / \mathrm{s})$ and to be highly resistant to heavy impact forces. It is applicable to flash floods and hurricane prone locations. The pavements and the walls where the panel needs to be installed, must have a surface pretreatment by means of a waterproof sealant. (Figure 6).

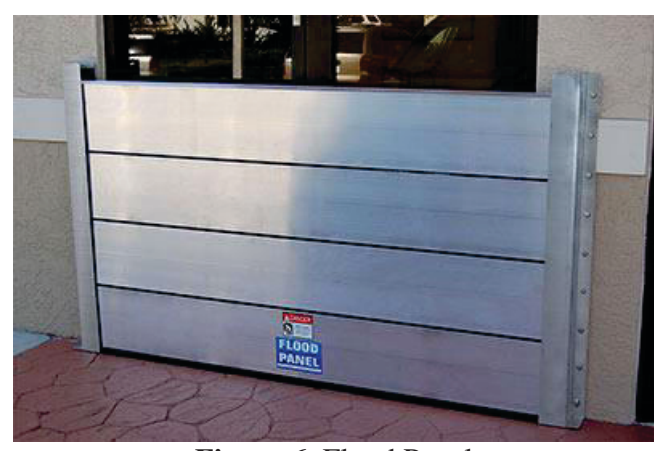

Figure 6. Flood Panel

\subsubsection{Geodesign Barriers}

The barriers consist of a robust frame, made of high quality galvanized steel and designed for steel barrier, board barrier, and pallet barrier (Figure 7).

The barriers can be installed along the riverbanks, in a street, in a garden, or any place where there is enough space (http://geodesignbarriers.com/). If they are installed on friction soils such as roads of asphalt or sand, there is no need of anchoring pins. They must be installed on cohesive soils such as clay or grass must use an anchor pin in each support to ensure maximum stability. Geodesign Barriers can be installed by a man and a forklift. With more staff and some trucks, a whole city can be protected in a few hours. The barriers are strong enough to withstand hard knocks from debris. The barriers for heights from 0.65 to 1.25 meters can resist for flows with $1-2 \mathrm{~m} / \mathrm{s}$ velocity. For higher velocities, even higher than $6 \mathrm{~m} / \mathrm{s}$, being that the flow is parallel to the barriers, are used for steel chains enclosed in the plastic membrane on the outer edge of the membrane itself. As long as the bottom of the plastic membrane does not erodes, it can bear any velocity.

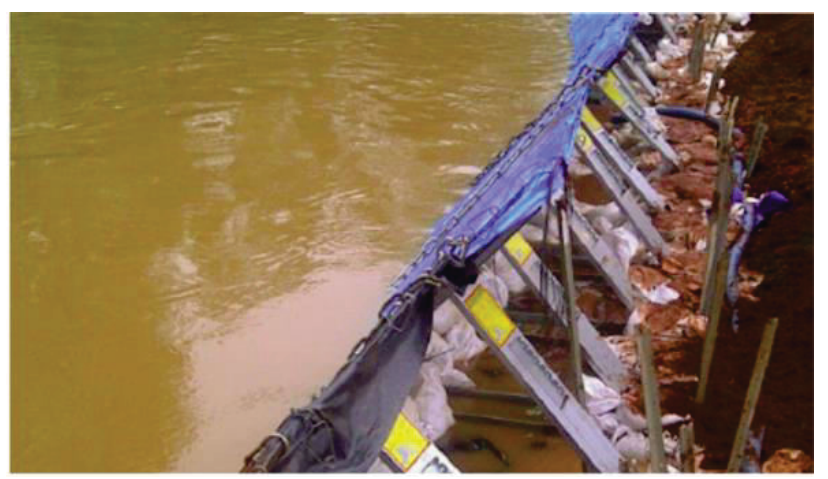

Figure 7. Geodesign Barriers

\subsubsection{FloodBreak}

The FloodBreak is a US company, created to offer a good defence to flooding (http://floodbreak.com/). The passive system of automatic barriers against floods provides a permanent and virtually invisible protection without the need for human intervention. During periods of nonflood, the barrier is located in the rest position, embedded in the head of embankment, and allowing normal pedestrian traffic or bicycle. The rising floodwater creates the hydrostatic pressure to float the buoyant aluminium 
beam and activate the self-sealing rubber gaskets. While the water rises, the flood barrier is lifted until it reaches $90^{\circ}$. The FloodBreak floodgate is actually a buoyant panel constructed of hollow aluminium extrusions. The extrusions are designed to be structural while also providing excellent flotation. They are designed for long straight and there is no limitation in length, can be used as levees along the banks of rivers.

Any product of FloodBreak withstands hydrodynamic forces, for water velocity until $11 \mathrm{~m} / \mathrm{s}$.

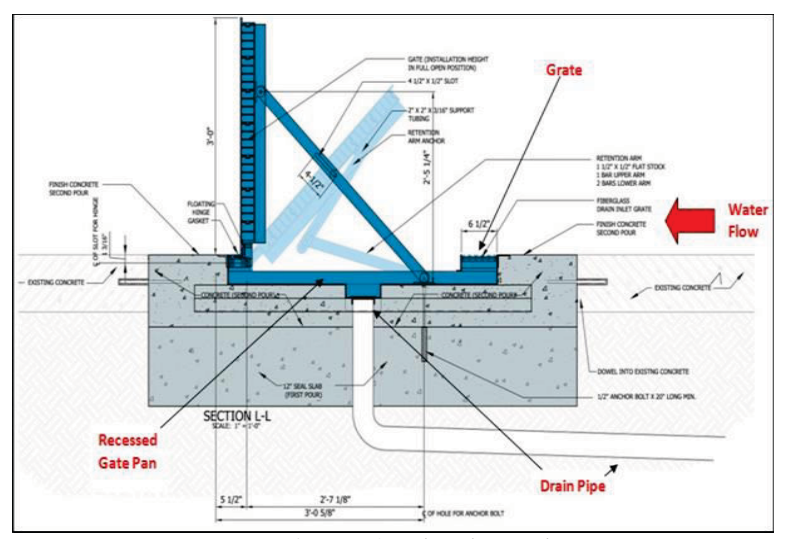

Figure 8. Flood Break

\subsubsection{Dutchdam}

Their barriers are composed by panels with standard length $2400 \times 250 \mathrm{~mm}$ (http://dutchdam.com/). The test laboratory of national institute DELTARES, demonstrated that collision of more than $400 \mathrm{kN}$ on a surface of some $\mathrm{dm}^{2}$ were absorbed by the entire wall, and heavy collisions with an object of $600 \mathrm{~kg}$ at a speed of $2 \mathrm{~m} / \mathrm{sec}$. at right angles to the wall did not cause damage. The supports of the Dutchdam are very flexible, such that, particularly with bigger defence wall heights, a huge amount of energy from any impact can be absorbed.

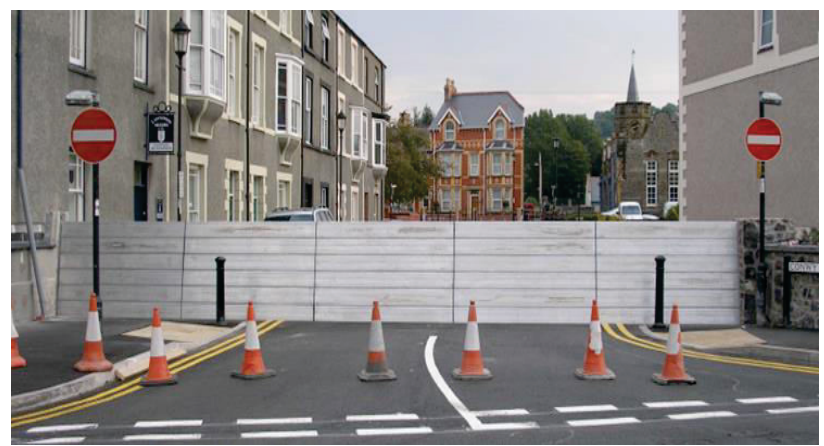

Figure 9. Dutchdam

\begin{tabular}{|c|c|}
\hline Flood Barriers & Resistance Force (N) \\
\hline Flood Panel & 13489 \\
\hline Geodesign Barriers & 10477 \\
\hline FloodBreak & 113589 \\
\hline Dutchdam & 20000 \\
\hline
\end{tabular}

Table 1. Resistance force of flood barriers

\section{Methodology}

In the event of November 2011, there have been significant economic damages, especially in the most economically active areas. The aim of this paper is to mitigate the flood risk, reducing the exposure of the richest areas [8]. To avoid that flood water hits rich areas, it was adopted a dry proofing strategy, in particular a shielding measure. MLFP-2D (Multi Level Flood Propagation) hydrodynamic model [9] has been used, to verify the effectiveness of the measure adopted. The flood barriers have been included in the model representation of the study area across the exposed roads, to divert the flow of water. To evaluate the effectiveness of this strategy, two different analysis, hydraulic and a static structural, have been carried out. MLFP-2D model was used for a first group of simulations, in order to understand where to place flood barriers, and thus avoiding that the water hits very exposed areas. In Figure 10 is shown the point where to place the barriers.

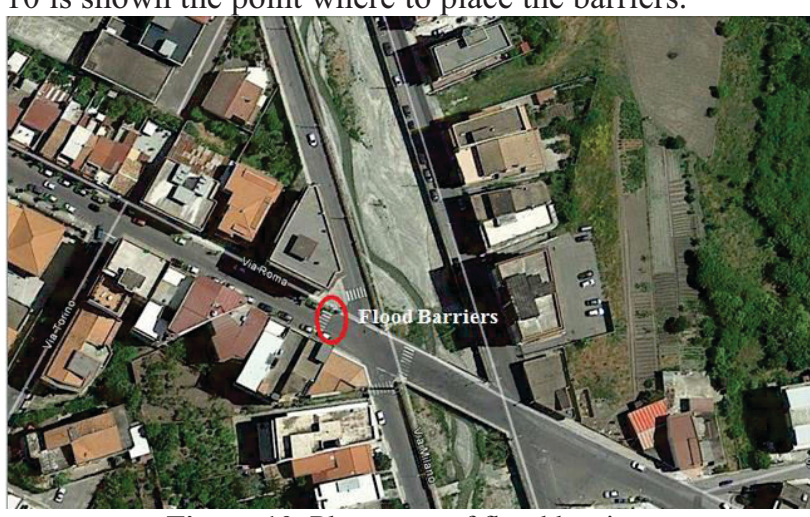

Figure 10. Placement of flood barriers

The model has been used with a triangular mesh, composed of 31814 nodes and 53081 elements. The Manning's roughness coefficients for river channel and for the street were calibrated in a previous work [10], and their values are respectively of 0.088 and $0.106 \mathrm{~m}^{-1 / 3} / \mathrm{s}$. The maximum peak flow rate used is of $212 \mathrm{~m}^{3} / \mathrm{s}$.

Simulations have been carried out with flood barriers of different heights, to find the optimum height, to prevent overtopping and not to increase the downstream flood risk. Furthermore, the force acting on the barriers was calculated combining the classical equations for hydrostatic and hydrodynamic force on a plane surface along a vertical wall [11:

$$
S=0.5 \rho g B h^{2}+\rho v^{2} B h
$$

where $\mathrm{S}$ is the sum of hydrodynamic and hydrostatic force, $\mathrm{B}$ is the width of 1 meter, $h$ is the maximum height of flood water on the barrier, $v$ is the horizontal component of velocity perpendicular to the wall, $g$ is the acceleration of gravity, and $\rho$ is the density of the flow calculated with the equation :

$$
p=c p_{s}+(1-c) p_{w}
$$

where $c$ is the solid concentration, $r_{\mathrm{s}}$ is the density of the solid, $\rho_{\mathrm{w}}$ is the density of the clear water. Finally, the forces resulted from the model have been compared with 
the stability values of the barriers provided by the producers.

\section{Results and discussions}

After simulations with the model MLFP-2D, it was found the optimum height of the flood barriers, with which it is possible to divert the flood flow, avoiding the inundation in the street and the increase of flood risk downstream.

In Figure 11 are represented the sections along the street, for which were compared to water height values, before and after the installation of the flood barriers. In figure 12, 13, 14 are shown the values of water depths, respectively, for the section A-A, B-B, C-C.

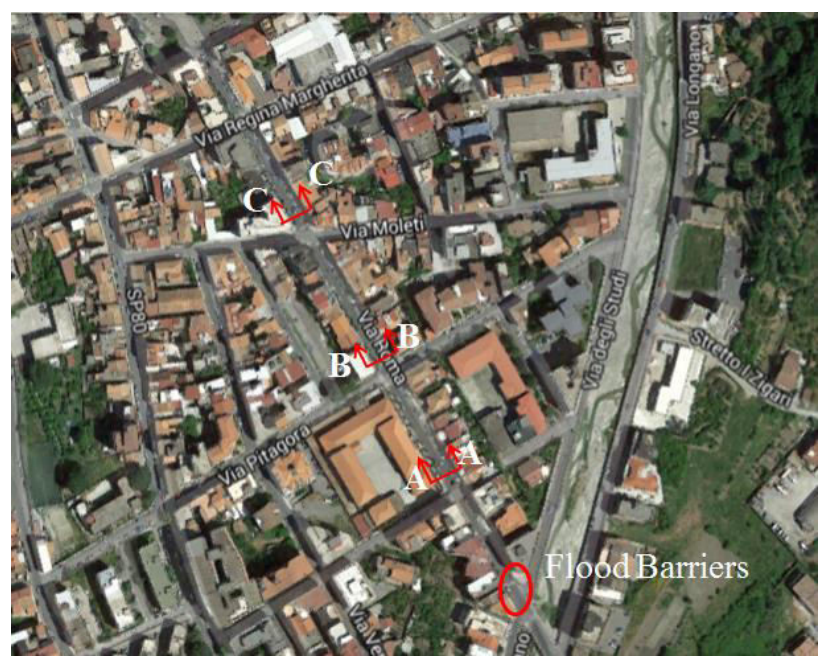

Figure 11. Analysed sections along a street

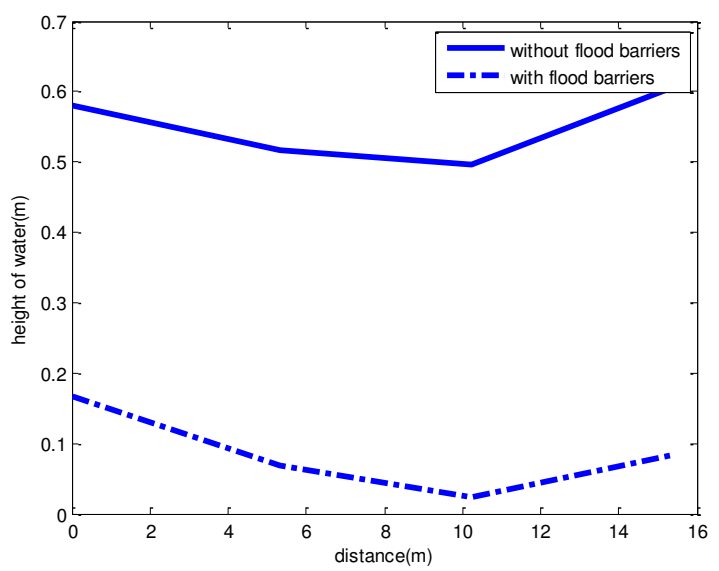

Figure 12. Water depths in section A-A

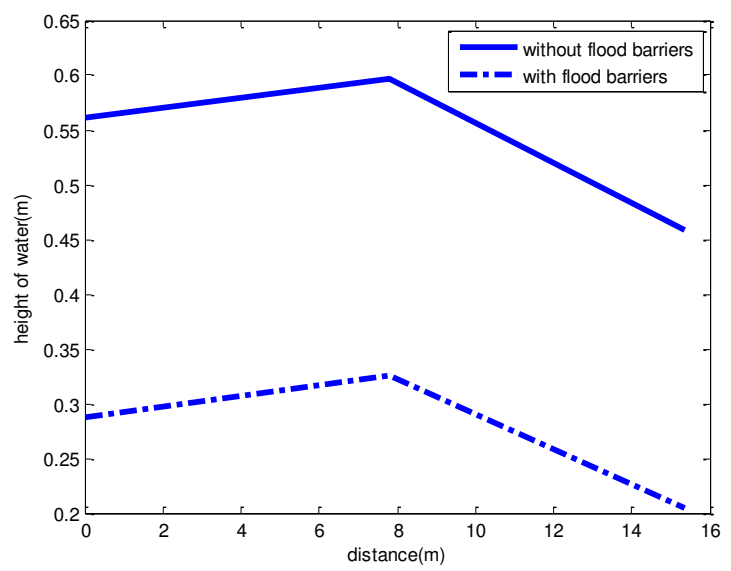

Figure 13. Water depths in section B-B

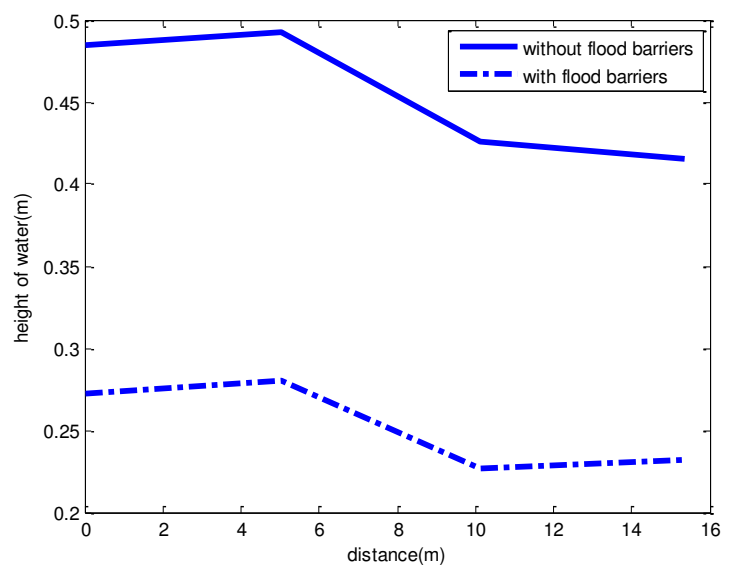

Figure 14. Water depths in section C-C

In the first part of the street, immediately after the flood barriers, the water flow is not present until the section AA. The figures 12,13 and 14 show the effectiveness of the flood barriers to reduce the water height along Via Roma, and therefore to divert the flow of water, without creating problems downstream. In fact, the water depth is decreased by about $30 \mathrm{~cm}$.

In Figure 15 and 16 are shown the velocity vectors, respectively before and after intervention. The size of the arrows is proportional to the velocity value. From the figures, it is possible to note that after the installation of the flood barriers across the road, as already mentioned above, in the first part of the street there is no more water flow, and in the second part the velocities are modest. In figure 15, after the installation of the flood barriers, is visible as the flow is parallel to the barriers, therefore in perpendicular direction there is only hydrostatic force. Therefore, the equation 1 becomes:

$$
S=0.5 \rho g B h^{2}
$$

The calculated force acting on the flood barrier for 1 meter wide is equal to $7587 \mathrm{~N}$, smaller of resistances forces of the various analysed barriers.

In conclusion, all the analysed flood barriers can be installed to divert the flow, but in the case of automatic flood barriers, (flood break) care must be taken, because when there are debris flow or mudflow, debris and mud may occlude the system and not allow a perfect 
functioning of the permanent flood barrier. Therefore, for this it is preferable to use temporary systems with manual installation. Further researches could compare the simulation results with measurements made in-situ, using flood barriers during a flood event.

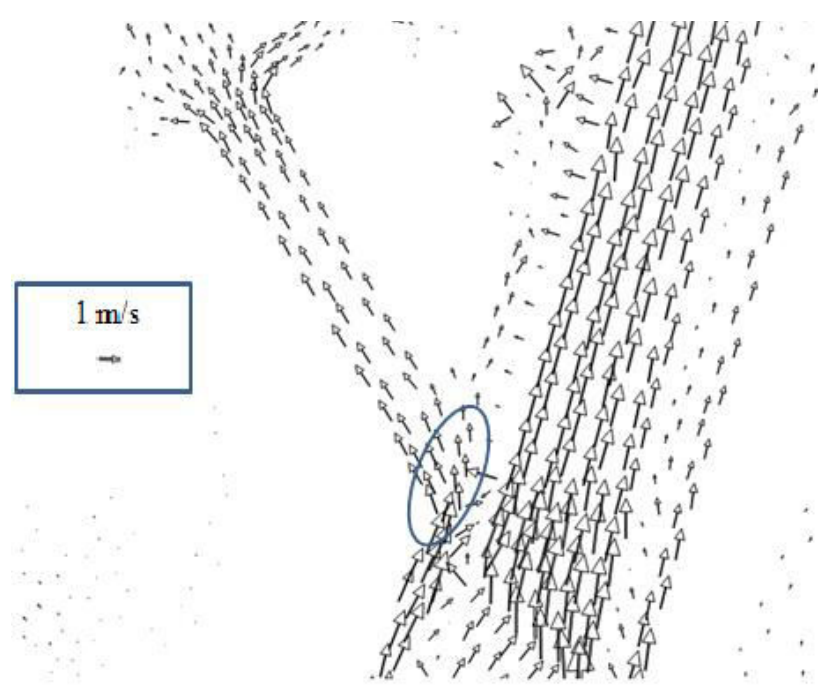

Figure 15. Velocity vectors without flood barriers

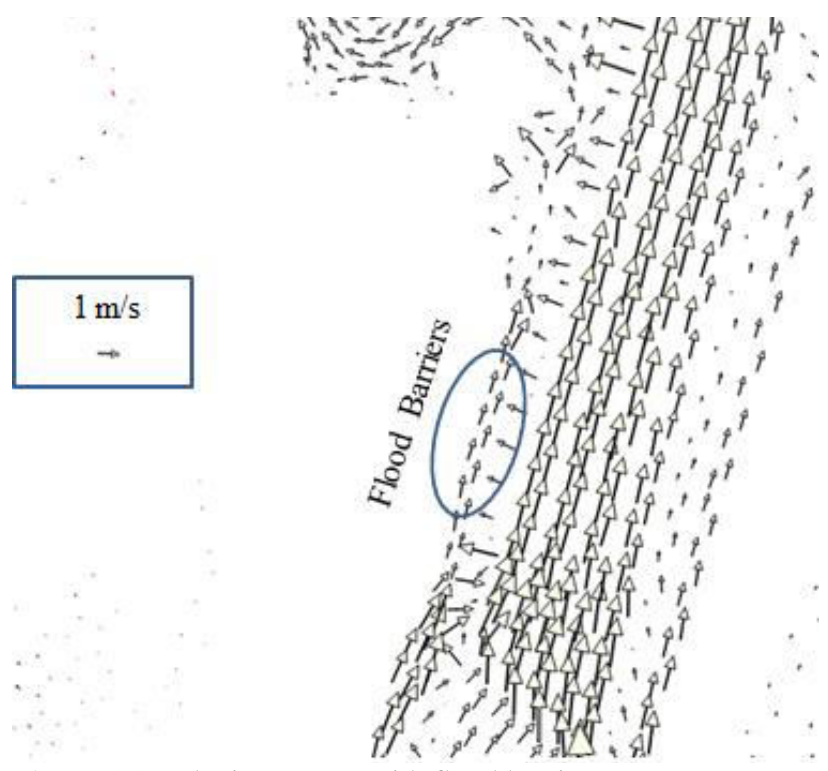

Figure 16. Velocity vectors with flood barriers

\section{References}

1. Zbigniew W. Kundzewicz, and Takeuchi K. (1999). Flood protection and management: quo vadimus?, Hydrological Sciences Journal, 44(3), 417-432.

2. Dhonau M., and Lamond J. (2012). Property-Level Flood Protection - Case studies of successful schemes. Flood hazards-Impacts and responses for the built environment, 291-303.

3. Johnson M. (2012). Protection and performance of flooded buildings. Flood hazards- Impacts and responsesfor the built environment, 259-267.
4. Manojlovic N. and Pasche E. (2007). Floreto-web based Advisory tool for flood mitigation strategies for existing buildings. Advances in urban flood management, 359-382

5. Salagnac J. (2007). An overview of flood protection barriers. Advances in urban flood management, 453 459.

6. Brilly M. (2007). Local flood defence systems in Europe. Advances in urban flood management, 321338.

7. Lamond J., Dhonau M., Rose C., and Proverbs D. (2009). Overcoming the barriers to installing property level flood protection - An overview of successful case studies. Road map towards a flood resilient urban Environment. Paris: Urban flood management cost action network $\mathrm{C} 22$.

8. Ashley R., Blanksby J., Chapman J. and Zhou J. (2007). Towards integrated approaches to reduce flood risk in urban areas. In Ashley R., Garvin S., Pasche E., Vassilopoulos A. and Zevenbergen C. (Eds.), Advances in urban flood management. London: Taylor \& Francis.

9. Aronica G., Nasello C., and Tucciarelli T. (1998). A 2D Multilevel Model for Flood Propagation in Flood Affected Areas. ASCE - Journal of Water Resources Planning and Management, Vol.124, n.4.

10. Giuseppe T. Aronica, Susanna Naso, Angela Candela, (2012). On the use of innovative post-event data for reducing uncertainty in calibrating flood propagation models. Uncertainty modelling in hydraulics Workshop.

11. Jarle T. Bjerkholt and Oddvar G. Lindholm (2007). An innovative semi-permanent flood protection structure- Alternative to sandbags and supplements to conventional earth embankments. Advances in urban flood management, 461-472. 